Artigo recebido: 01/08/19

Artigo aprovado em: 28/11/19

\title{
CONHECIMENTOS, EXPERIÊNCIAS E PRÁTICAS VITAIS TRADICIONAIS INDÍGENAS COMO FUNDAMENTO PARA A CONSTRUÇÃO DE UMA CULTURA DE SUSTENTABILIDADE
}

\author{
José Capitango ${ }^{1}$ \\ Germán Vargas Callejas ${ }^{2}$
}

\section{RESUMO}

O presente estudo objetiva valorizar aqueles aspetos das culturas tradicionais (conhecimentos, estilos de vida...) que podem servir de fundamento para a construção e cultivo de uma cultura de sustentabilidade a nível global. A informação que sustenta este estudo provém do projeto "Processos e práticas educativas para a transição a uma cultura da sustentabilidade e a cooperação em Galícia e República Dominicana - Investigação-Ação", como também da tese em processo de elaboração sobre "Educação e Desenvolvimento nas Comunidades Ovimbundu de Angola: Estudo etnográfico da Comunidade de Ombala EkovongoBié/Angola" (investigação etnografica). Trata-se de uma tentativa de aproximar as duas realidades histórico-culturais (africana, latino-americana), naquilo que as suas populações indígenas têm de comum em termos de conhecimentos e experiências para subsidiar a construção da cultura de sustentabilidade.

Palavras-chave: conhecimentos; experiências vitais tradicionais indígenas; cultura de sustentabilidade

\section{INDIGENOUS TRADITIONAL KNOWLEDGE KNOWLEDGE, EXPERIENCE AND PRACTICE AS A BASIS FOR BUILDING A SUSTAINABILITY CULTURE}

\begin{abstract}
The objective of this study is to value those aspects of traditional cultures (knowledge, lifestyles ...) that can serve as the foundament for the construction and cultivation of a culture of sustainability at a global level. The information that supports this study comes from the project "Educational processes and practices for the transition to a culture of sustainability and cooperation in Galicia and the Dominican Republic - Research-Action", as well as the thesis in the process of elaboration on "Education and Development in Ovimbundu Communities of Angola: Ethnographic study of the Ombala Ekovongo-Bié / Angola "community (Ethnographic Research). It is an attempt to bring together two historical-cultural realities (African and Latin American), in what their indigenous populations have in common in terms of experience and knowledge, to subsidize the construction of culture of sustainability.
\end{abstract}

Keywords: knowledge; traditional indigenous life experiences; culture of sustenability

\footnotetext{
1 Instituto Superior de Ciências da Educação de Luanda-Angola. E-mail: Josecapitango@yahoo.com.br

${ }^{2}$ Universidade de Santiago de Compostela Galicia - España. E-mail: german.vargas@usc.es
} 


\section{INTRODUÇÃO}

A humanidade enfrenta uma crise complexa que resulta de um processo de construção socio-histórica, cuja origem remonta a aurora da modernidade, enquanto expressão máxima de realização do capitalismo liberal e das múltiplas contradições que Ihe são inerentes. Mais do que limitá-la apenas ao âmbito natural, a crise é estrutural e, por conseguinte, civilizacional, porquanto, remete para a necessidade de análise de outras dimensões (social, cultural, espiritual, moral, estética, ambiental, económica, política, etc.) que circunscrevem e dão sentido à vida. A estrutura socioeconómica e socioorganizacional adotada pelos países do centro e imposta aos países do capitalismo periférico continua a gerar impactos negativos sobre a esfera social e aos ecossistemas, dependendo do estádio de desenvolvimento, das tecnologias produtivas adotadas, da quantidade e qualidade de recursos envolvidos e do modo como os mesmos são utilizados para satisfazer as necessidades do sistema Moreno (2011) e dos interesses de seus mentores.

O modelo de sociedade adotado nos últimos cinco séculos e os processos de desenvolvimento aplicados para a sua concretização contribuíram na construção e afirmação de uma mentalidade linear, baseada na racionalidade antropocêntrica que eleva o ser humano à condição de um ente sobrenatural, depredador na relação com a natureza Vargas (2019), da qual se separa voluntariamente, apesar de ser esta a fonte de onde obtém recursos necessários para a satisfação das suas necessidades. Ao longo deste período, o homem foi criando instrumentos através dos quais operou transformações ao meio envolvente, provocando mudanças não só na natureza, mas também na estrutura social, isto é, idealizou um modelo de desenvolvimento que promove, ainda nos dias de hoje, o individualismo, a ganância, a competição e a violência nas relações sociais, culturais, económicas, políticas, etc. Estes fatores têm obrigado o homem a empreender ações consubstanciadas na exploração desregrada de recursos naturais, principalmente daqueles demandados pela indústria cada vez mais tecnologizada, para a produção de bens que se destinam à satisfação das 
ambições consumistas, provocando com tais ações desequilíbrios nos ecossistemas.

O presente estudo objetiva valorizar os aspetos da cultura indígenas (conhecimentos, estilos de vida, etc.) que podem servir de fundamento para a construção e cultivo de uma cultura de sustentabilidade a nível global. Partimos da hipótese de que a humanidade precisa de um rumo partilhado, uma cosmovisão que dê lugar a uma nova utopia humana, capaz de mostrar um horizonte ao qual se dirigem os esforços das pessoas; uma cultura de sustentabilidade que assenta na comunidade, na interculturalidade, na interdependência, na cooperação, na eco-dependência, no respeito aos limites da natureza e a todas as formas de vida Vargas (2019), mediada por uma visão de cidadania global.

O estudo permite compreender, primeiro, que como humanidade precisamos desenvolver novas utopias, que sirvam de ponte para a integração de todas as iniciativas geradas a partir de práticas sustentáveis; segundo, que em grande medida contamos com os conhecimentos e os saberes provados para a prática de uma vida mais sustentável; terceiro, que a possibilidade de um futuro humano passa pelo questionamento das atuais formas de relacionamento com a natureza e as práticas culturais vigentes; quarto, precisa-se de uma educação ambiental que destaque os valores das populações autóctones e indígenas e que, ao mesmo tempo crie espaços de diálogo para a construção coletiva e global de um novo destino humano.

O estudo estrutura-se em quatro apartados: o primeiro, resenha 0 panorama da crise mundial, suas causas e seu impacto nas sociedades contemporâneas; no segundo, desenvolve-se a conceptualização da sustentabilidade como paradigma e seus desdobramentos para as várias dimensões da vida (económica, social, cultural, etc.); no terceiro e quarto apartados esboçam-se os fundamentos da sustentabilidade na cosmovisão africana e indígena latino-americana, e no fim apresentam-se as conclusões do estudo.

\section{A CRISE AMBIENTAL COMO EXPRESSÃO DA CRISE GLOBAL}

A atual crise ambiental é um fenómeno complexo que resulta de um processo de construção histórica, cuja origem remonta a aurora da 
modernidade. Nos últimos cinco séculos, desenvolveu-se uma civilização baseada na exploração da natureza e o ser humano, para construir um modelo civilizatório dominante do qual sobressai a lei do mais poderoso em capacidade de consumo, força militar, riqueza e influência política, hegemonia religiosa entre outros; um modelo de vida que, desde uma leitura em termos de indicadores sociais e ambientais, configura, em palavras de Batanoli e Milioli (2016)

“ (...) um cenário em que devastação ambiental, contradições económicas, urbanização desumanizante, degradação dos valores básicos da civilidade, hegemonia dos valores materiais nas relações humanas, reflexos éticos da grandeza material a qualquer custo, aumento vertiginoso de doenças psíquicas e outras denominadas "doenças da civilização" em caracter quase epidémico, aumento exponencial do consumo de drogas de todos os tipos, e tantos outros, se mostram articulados, não deixando dúvidas: existe uma crise multifacetada, mas de natureza única e de abrangência planetária. (Batanoli e Milioli, 2016, p. 38)

A crise ambiental é uma das manifestações nefastas resultantes da coisificação da natureza, da insustentabilidade dos limites dos desequilibrios ecológicos, dos excessos da injustiça social e da fragmentação do mundo para permitir o seu domínio e controlo. A crise ambiental é acima de tudo uma crise da epistemologia Leff (2004) na base da qual se ergueu a civilização ocidental, cuja realização alimentou falsas esperanças de uma modernidade comprometida com o progresso de toda a humanidade. A crise é global, pois, apesar da propalada globalização económica e tecnológica encontrar alguma recetividade pelo mundo, a mesma não decorre sem resistências, porquanto, longe de ser um processo unificador ou integrador promove o desrespeito aos valores que estruturam o mundo e dilui toda a esperança no progresso da humanidade. A angústia em relação ao futuro dos valores culturais e das identidades nacionais, étnicas e religiosas Morin (2011) engendra desconfianças e bloqueia o espirito cooperativo entre os povos; um conjunto de problemas sociais agravados pela degradação dos ecossistemas e nos modos de vida cuja expressão mais nociva se reflete no meio ambiente, onde se pode identificar um conjunto de fenómenos:

Nos países industrializados, contaminação das águas, inclusive dos lençóis freáticos; envenenamento dos solos por excesso de pesticidas e fertilizantes; urbanização maciça de regiões ecologicamente frágeis (como as zonas costeiras); chuvas ácidas; depósito de detritos nocivos. Nos países não industrializados, 
desertificação, desmatamento, erosão e salinização dos solos, inundações, urbanização selvagem de megalópoles envenenadas pelo dióxido de enxofre (que favorece a asma), o monóxido de carbono (que causa problemas cerebrais e cardíacos), o dióxido de azoto (imuno-depressor). (Morin e Kern, 2003, p. 69)

A crise global expressa um questionamento ao projeto civilizatório pelo qual se procurou realizar a homogeneização do mundo através de uma razão totalizadora. A sua superação não poderá ocorrer se não for desconstruida a base ontológica e epistemológica que legitima a sua existência.

\section{A SUSTENTABILIDADE COMO PARADIGMA DO SÉCULO XXI}

O paradigma da sustentabilidade tem vindo a animar os debates em instituições académicas e em fóruns internacionais com destaque para a Conferência das Nações Unidas sobre o Meio Ambiente e Humano, realizado em Estocolmo/1972, a Conferência das Nações Unidas sobre o Meio Ambiente e Desenvolvimento realizada em Rio de Janeiro de 1992, que adotou a Agenda/21, a Cúpula Mundial do Desenvolvimento Sustentável (Rio+10), realizada em Joanesburgo/2002, a Conferência das Nações Unidas sobre 0 Desenvolvimento Sustentável (Rio+20) que se realizou em 2012 no Brasil, e a Cúpula Mundial sobre o Desenvolvimento Sustentável realizada em 2015 na cidade de Nova York, tendo esta última adotado a Agenda/2030 sobre a realização dos Objetivos de Desenvolvimento Sustentável (ODS) à escala mundial.

$\mathrm{Na}$ senda da realização destes eventos, delineiam-se horizontes para uma melhor compreensão da magnitude da crise ambiental e global, e inaugura-se um longo processo de elaboração de propostas que, eventualmente, poderão permitir a concepção de um modelo de desenvolvimento, que seja capaz de construir uma cultura de sustentabilidade assente na comunidade, na interculturalidade, na cooperação, na ecodependência, no respeito aos limites da natureza, à equidade entre as pessoas que habitam o nosso planeta.

A sustentabilidade começa a suscitar uma atenção cada vez maior nos modos de pensar do ser humano, e nos mais variados âmbitos (individual, familiar, grupal ou étnico, institucional e internacional), que caracterizam a organização da vida e das sociedades, devido, sobretudo, à eclosão da crise 
ambiental e global atrás descrita que assola o nosso planeta. Este despertar de consciências vislumbra uma nova visão de ser e estar no mundo que, em nosso entender deve assentar numa reconciliação entre os saberes provenientes da racionalidade cientifico-tecnológica e os saberes da tradição das populações indígenas elaborados a partir de uma postura de reverência do homem para com a natureza. Assim, se a liberdade se constitui em paradigma dominante na ciência, nas relações sociais e no direito para a modernidade, a sustentabilidade emerge como um novo paradigma da pós-modernidade e na contemporaneidade, para redefinir as pautas axiológicas que orientam a conduta das pessoas ao nivel local, nacional, internacional e global Glasenapp e Cruz (2013). Este novo modo de ser, estar e agir implica uma consciência que transcenda os limites dos direitos subjetivos e obrigações individuais de posse de propriedade Ost (1995) para se situar num quadro mais amplo dos direitos de todos os seres da natureza incluindo os das gerações futuras.

A ciência e a produção cientifica precisam construir uma epistemologia que restitua o lugar do homem na natureza; ao mesmo tempo que, desconstrua a ideia dominante de conquista da natureza por esse mesmo homem para constituir a riqueza material, porquanto a maior riqueza da humanidade consiste na capacidade de manter equilibrios climáticos, ecossistémicos, ou seja, da biosfera em sua totalidade. O homem moderno ainda não compreendeu quão destrutivo é a sua racionalidade; as suas realizações cientificas e tecnológicas permitiram a construção de instrumentos tão sofisticados que parece ter-se libertado das superstições, mas, em contrapartida perdeu as suas tradições e os valores espirituais Cavalcanti (1994) que são os ingredientes essenciais que orientam e dão sentido à vida.

A atual noção de sustentabilidade é tendencialmente antropocêntrica e assenta acima de tudo na lógica utilitária dos recursos para a satisfação das necessidades humanas. A sustentabilidade enquanto paradigma do século XXI interpela o homem a rever a sua relação com a natureza e a sua posição no universo, o que implica uma visão holistica do funcionamento dos ecossistemas e uma compreensão profunda da realidade da própria biosfera da qual depende o futuro da humanidade.

A sustentabilidade é um paradigma, uma racionalidade que assenta nos princípios democráticos de abertura, diálogo e reconhecimento das mais 
diversas fontes de conhecimento, rompendo deste modo com a pretensão do pensamento científico dominante e linear, que se mostra insuficiente para dar soluções à problemática ambiental e à crise global. Pelo seu carácter dinâmico, a sustentabilidade precisa de ser analisada com uma perspetiva multidimensional que em palavras de Belchior e Viana (2016) deve considerar os “(...) aspetos ambientais, sociais, económicos, políticos, culturais e espirituais" (p. 84). A sustentabilidade é paradigma do século XXI marcado por uma transição da modernidade inacabada para a pós-modernidade que privilegia a autonomia, a democracia, a diversidade e a equidade nas relações entre os humanos e entre estes com a natureza. Trata-se de um novo modelo de organização socioeconómica que rompe com 0 atual modelo de desenvolvimento impulsionado pelo consumo para outro, em que os cidadãos se sentem mais comprometidos com a manutenção dos ecossistemas e a sobrevivência da especie humana.

A sustentabilidade emerge como um paradigma civilizatório, em cuja vigência se opera uma ruptura com o paradigma da modernidade para se afirmar, não como uma doutrina homogênea e acabada, mas sim, como um campo aberto onde se intercruzam ideologias heterogêneas que atendem a uma multiplicidade de interesses, práticas culturais e sociais. Trata-se de uma problemática ecológica de alcance planetário que afeta todas as classes sociais, que abre horizontes para um processo de transformações epistémicas na produção do conhecimento e desenvolvimento das tecnologias. Com esta perspectiva, o paradigma da sustentabilidade não pode ser analisado à margem dos saberes indígenas, dos seus sistemas gnoseológicos, dos seus valores culturais e das suas práticas tradicionais de utilização dos recursos naturais Leff (2013). Assim, a sustentabilidade deve ser analisada em articulação com os saberes tradicionais elaborados pelas comunidades indígenas, que mesmo não sendo considerados de científicos revelaram-se eficientes ao longo de séculos. Esta postura vem ao encontro do disposto na Covenção das Nações Unidas sobre a Biodiversidade adotada em 20 de Maio de 1992, que no seu artigo 8ํㅡㄴ (alínea j) recomenda aos Estados Membros o seguinte:

De acordo com a sua legislação, respeitar preservar e manter o conhecimento, as inovações e práticas das comunidades indígenas e locais que envolvam estilos tradicionais de vida relevantes para a 
conservação e utilização sustentável da diversidade biológica e promover a sua aplicação mais ampla, com a aprovação e participação dos detentores desse conhecimento, inovações e práticas, e encorajar para que os benefícios derivados da utilização desse conhecimento, invações e práticas sejam equitativamente partilhados.

Desta feita, o paradigma da sustentabilidade reafirma a necessidade de um renascimento cultural dos povos indígenas que permaneceram durante séculos numa condição de marginalizados e subjulgados pelos regimes coloniais e similares que distorceram os valores da sua ética ambiental impondo-Ihes uma ideologia contrária à sua racionalidade.

\section{Aproximação ao conceito de sustentabilidade}

Os aspetos atrás espelhados tornam difícil a conceptualização da sustentabilidade por ser um termo que corporiza múltiplas dimensões interdependentes (ambiental, social, económica, cultural, política, ética, etc). 0 termo é polissémico e heterogéneo, pois admite múltiplas possibilidades de entendimento com reconhecimento em distintos campos do conhecimento. De acordo com o Dicionário Prático ${ }^{3}$, sustentabilidade vem do latim sustentare que quer dizer aguentar, manter, resistir, suportar, ou seja, evitar a queda e manter o equilíbrio. Para Loureiro (2012) o conceito de sustentabilidade é instigante, complexo e desafiador, pois abre múltiplas possibilidades de desdobramento do termo, posto que, o mesmo vem das ciências biológicas e estende-se até à esfera política, na economia, na cultura, etc. Nesta linha, a sustentabilidade pode ser analisada sob a perspetiva multidisciplinar.

Herrero (2000) considera a sustentabilidade em termos puramente ecológicos, definindo-a como a capacidade para manter constante o tempo de vitalidade dos seus componentes e processos de operação. Ferrer (2012) define a sustentabilidade com uma perspetiva jurídica e afirma:

\footnotetext{
En términos jurídicos, el derecho de la sostenibilidad es un derecho pensado en términos de espécie y en términos de resolver problemas globales. Trae parte de la estrutura clássica de los órdenes jurídico, social, económico, y ambiental, que son própio de los estados soberanos, pero desborda claramente esse ámbito. Su vocación es aportar soluciones que sirvan a todos, sin importar dónde se encuentren o dónde nacieran. Pretende aportar la esperanza de una sociedad futura global y mejor. (p. 320)
}

${ }^{3}$ Dicionário Prático, Lello Editores, 2001. 
$\mathrm{Na}$ mesma senda e com o intuito de atribuir maior responsabilidade aos estados, Freitas $(2012)^{4}$ define a sustentabilidade nos seguintes termos:

(...) trata-se do princípio constitucional que determina, com eficácia direta e imediata, a responsabilidade do Estado e da sociedade pela concretização solidária do desenvolvimento material e imaterial, socialmente inclusivo, durável e equânime, ambiente limpo, inovador, ético e eficiente, no intuito de assegurar, preferencialmente de modo preventivo e precavido, no presente e no futuro, o direito ao bemestar.

Para Canotilho (2010) a sustentabilidade é um imperativo ético e chama a atenção aos humanos para que as suas ações e os seus comportamentos não se traduzam no sofrimento de outras nações e muito menos anulem o direito das futuras gerações de usufruírem dos recursos naturais. O autor adverte: "os humanos devem organizar os seus comportamentos e ações de forma a não viverem: (i) à custa da natureza; (ii) à custa de outros seres humanos; (iii) à custa de outras nações; (iiii) à custa de outras gerações" (p. 8). Este autor associa ao conceito de sustentabilidades três dimensões básicas: (1) a sustentabilidade interestatal que deve permitir a equidade entre países pobres e países ricos; (2) a sustentabilidade geracional que deve promover a equidade entre diferentes grupos etários da mesma geração; (3) a sustentabilidade intergeracional pela qual se deve assegurar a equidade entre aqueles que vivem o presente e aqueles que hão de nascer no futuro.

A sustentabilidade tornou-se um imperativo de sobrevivência da humanidade no sentido de preservação da biodiversidade e dos ecossistemas, cuja materialização perpassa pela introdução de mudanças nos modos de exploração de recursos naturais destinados à satisfação das demandas económicas e alteração nos hábitos de consumo que encorajam a aventura humana na sua determinação de dominar a natureza. Como se pode perceber analisar o conceito de sustentabilidade é uma tarefa desafiadora, que congrega uma série de dimensões, sem as quais a sua compreensão permaneceria incompleta. Os aspetos sociais, económicos, jurídico-políticos, culturais e éticos, e tantos outros influem no conceito de sustentabilidade. Por exemplo, os problemas ecológicos já não podem ser analisados unicamente nos laboratórios das ciências; o diálogo com outros saberes faz-se necessário, uma

\footnotetext{
${ }^{4}$ Freitas citado por Mafra (2015) O Paradigma da Sustentabilidade no Ordenamento Jurídico Brasileiro: Um Direito Fundamental Material, UNIVALI, Itajai, vol 10 № 1 p. 554
} 
vez que, os mesmos derivam, em grande parte dos aspetos atrás referenciados.

A sustentabilidade emerge, por um lado, como uma ruptura epistemológica de uma racionalidade objetivista e homogeneizadora, para dar lugar a intersubjetividade na análise de fenómenos ambientais que afetam a esfera social, cultural, e económica; por outro, como um imperativo de mudança, de uma mentalidade predatória e hegemónica, para outra de reverência à vida, e respeito pela diversidade cultural de todos os povos que habitam o nosso planeta.

Para as populações injustiçadas e empobrecidas por imposição destes processos de ocidentalização em todo o mundo, e, em particular as populações indígenas de África, América latina e Ásia, a sustentabilidade constitui uma nova etapa evolutiva, não somente de reivindicação dos direitos humanos (económicos, culturais, sociais, etc.), mas também de reafirmação e reapropriação dos saberes (tradicionais, culturais e ambientais, ecológicos, medicinais, etc.) por si elaborados e preservados ao longo da história.

\section{Os fundamentos da sustentabilidade na cosmovisão Africana}

Qualquer sociedade, por mais diminuta que seja, possui um espaço delimitado e uma cultura, o que pressupõe a existência de relações de ordem ideológica, institucional e técnicas. Em África coabitam várias tradições civilizacionais de entre as quais se destacam a civilização da floresta, da savana, das montanhas, de pastores e de agricultores. Apesar das adversidades, das múltiplas tradições e do tipo de atividades que exercem em função do meio que habitam, prevalece entre elas um aspeto convergente - a unidade cultural africana, por vezes designada como africanidade ou identidade africana. Esta comunhão de índole cultural se fundamenta na religião tradicional que partilham todas as sociedades africanas pré-coloniais, pré-islâmicas e pré-cristãs. Esta religião tradicional radica essencialmente numa crença à Deus, à natureza, à pessoa aos ritos consagrados, uma comunidade de crentes, um corpo de oficiais, um calendário, um altar e áreas sagradas Gadou (2001), que em conjunto transmitem uma visão de mundo, uma concepção geral do universo, da vida e de homem, uma totalidade 
coerente que informa continuamente a alma ${ }^{5}$ dos povos. Memel-Fotê (1998) descreve de forma sucinta desta cosmovisão africana nos seguintes moldes:

\begin{abstract}
Segundo as cosmogêneses africanas, quatro elementos entram na formação deste mundo. O primeiro elemento, isto é, o fogo, energia celestial, manifesta-se no calor e na seca, correspondendo à estação seca; o fogo gera o segundo elemento, o Ar, que se manifesta no calor e na humidade; é do ar que vem, em forma de chuva, o terceiro elemento, a Água, síntese da humidade, do calor e da seca, a água é o "elemento essencial da vida, vida florestal, vida antes de vida, vida antes da vida exterior; da água vem o quarto elemento, a Terra, outra síntese dos três elementos. Enfim, da terra nasceram, por ordem cronológica, o vegetal, o primogênito, o animal, o mais novo; e o homem, o mais jovem entre os seres animados. Além disso, este mundo, entre os africanos, é subdividido em duas esferas; um, visível e o outro, invisível, mas ambas são interrelacionadas perpétuas pelo jogo dos poderes invisíveis. O mundo invisível perceptível por aqueles que têm uma dupla visão, isto é, os nyctosophes ${ }^{6}$ (adivinhos, videntes, feiticeiros) é o submundo, habitado por gênios e antepassados, donos e senhores da terra. Quanto ao mundo visível, é o espaço entre o céu e a terra, sendo o céu o lar do Ser Supremo: enquanto a terra é o espaço ocupado por seres viventes: os homens, os animais, as águas, as plantas. Também no seio do mundo visível, o antigo africano distingue dois espaços: o espaço socializado ou cultural que é aquele que o homem habita e o espaço não socializado ou natural que é o interior dos deuses intermediários mais ou menos benevolentes, cujas montanhas, densas florestas, ilhas, águas, pântanos, corredeiras, profundidades e alturas são santuários. (Memel-Fotê em Gadou, 2001, pp. 181-182) ${ }^{7}$
\end{abstract}

Como se pode perceber, nestas entrelinhas, a finalidade da existência do homem neste mundo está estabelecida no universo e é influenciada pela ordem dos seres na natureza. Ela é independente dos desejos do homem mesmo das suas aspirações mais sublimes. $O$ homem africano estabelece um parentesco original com a natureza, porque entende que esta é a única arte de que dispõe para viver sem turbulências. Se para o homem ocidental a maior realização é dominar a natureza, obter o capital e o poder económico a todo custo para ostentar e dar visibilidade de seu estatuto social, para o Africano, o projeto maior da vida é encontrar o equilíbrio e harmonia com a natureza. $O$ universo se compõe de dois espaços distintos: um invisível habitado por entes espirituais e outro visível habitado por homens, animais, vegetais onde fazem parte os minerais. Os vegetais simbolizam a fecundidade e a vida em geral. Por isso, os africanos recorrem à floresta para realizar o rito de iniciação (masculina ou feminina) como forma de penitência a Deus para providenciar a fecundidade

\footnotetext{
${ }^{5}$ Nas línguas africanas a palavra alma significa espirito e vice-versa.

${ }^{6}$ Nyctosophes são pessoas que veem melhor de dia que de noite.

7 Tradução própria.
} 
destas novas criaturas ${ }^{8}$, os neófitos. Unido deste modo à natureza, o homem africano reconhece que a mesma é povoada por poderes benfeitores e malfeitores.

Na cosmogénese africana, a natureza tem um simbolismo representado por vegetais, animais e minerais; a vida como substância do mundo manifestase em primeira instância nos vegetais e é representada pela árvore. Com efeito, é da terra, síntese de outros elementos (Fogo, Ar e Água) que brota a vida sob forma de vegetais; a árvore simboliza a vida humana que adquire a raiz a partir da terra profunda dos ancestrais e se expande no tronco e nas folhas; entre a raiz, o tronco e as folhas existe uma comunicação perpétua que circula de maneira incessante ligando a terra com o mundo do além. Desta feita, a árvore tem uma importância incomensurável, porquanto, para se alimentarem e curar as enfermidades, o homem e o animal recorrem aos frutos, às folhas, à casca e às raízes da árvore. A sua vocação é manter a vida dos seres vivos, em particular dos seres humanos. A árvore é a mediadora genética da vida universal; a Terra e o Céu formam um par primordial que gera ao mundo todos os seres que são também irmãos uterinos e consanguíneos Gadou (2001).

Esta visão fundamenta o grau de afetividade que os africanos têm na relação com a natureza a que devem reverência porque se sentem protegidos por ela; é também a base da irmandade e solidariedade que as pessoas da mesma família alargada, comunidade ou etnia estabelecem entre si. A solidariedade começa na família alargada e se estende até à comunidade, o que faz com que cada membro se sinta em segurança. No entanto, esta irmandade e solidariedade implica uma reciprocidade, de tal forma que, dela não pode beneficiar aquele que não a pratica. Este princípio preside as relações entre os seres do universo e se extrapola para as relações sociais que os seres humanos estabelecem entre si.

\footnotetext{
${ }^{8}$ Anais do III Encontro Nacional do GT de História das religiões e das religiosidadesANPUM, vol. III n ${ }^{\circ} 9$ Janeiro/2011.
} 


\section{Conhecimentos e experiências práticas tradicionais de sustentabilidade em África.}

Os estudos que veem sendo realizados nos países africanos estimam que mais de $\quad 80 \%$ da população sobrevive de recursos naturais Butaré (2003) graças ao vasto e profundo conhecimento de práticas tradicionais de gestão sustentável do meio em que habita. Pese a incomensurável importância que os recursos naturais representam para a sobrevivência das populações africanas em termos de produção alimentar, tratamento de enfermidades, etc, se constata que o crescimento demográfico, a urbanização desordenada, as queimadas, a adoção de técnicas modernas de monocultura, a exploração desregrada de recursos naturais e a erosão cultural constituem uma séria ameaça à conservação e à preservação dos ecossistemas e da biodiversidade nesta subregião do mundo. Não obstante, em toda a África regista-se um fervoroso movimento de renascimento cultural africano, cuja bandeira consiste na revitalização dos conhecimentos e das experiências práticas tradicionais que ao longo de séculos permitiram uma gestão sustentável dos ecossistemas, da biodiversidade e do meio ambiente.

Nas diferentes culturas tradicionais africanas o indicador comum em matéria da sustentabilidade é a visão holística das relações que associam o homem, não somente ao ambiente, visto no plano material e imaterial, mas também as representações que orientam as suas condutas, sancionadas pela reverência para com as montanhas, as florestas, as árvores e outros vegetais, algumas espécies de animais sagrados, às interdições de ordem mística, totémica, costumeira e jurídica, bem como aos saberes técnicos, das práticas culturais de exaltação da beleza natural expressa através da arte representativa e da oralidade, ou seja, por intermédio de objetos de arte, legendas, contos, mitos, récitas, poesia e canções Sanou.

Entre os ovimbundu de Angola ${ }^{9}$ existe a tradição de sacralização das lagoas, das montanhas e de algumas espécies da fauna ${ }^{10}$. Assim, o cágado

\footnotetext{
${ }^{9}$ Os ovimbundu de Angola constituem o grupo alvo do estudo que dá corpo a Tese de Doutoramento em curso de nossa autoria.

${ }^{10}$ Os ovimbundu observam minunciosamente o comportamento dos animais domésticos (cães, galinhas, etc.) para informarem-se da presença de entes invisíveis, assim como de espécies selvagens (aves, gafanhotos, formigas, salalé, etc) para predizer eventos climáticos futuros.
} 
simboliza a sensibilidade, a prudência e a inteligência do Rei; o elefante e o hipopótamo simbolizam a longevidade e a supremacia do Poder Real. Algumas espécies de aves como humbi-humbi, são aves que raramente aparecem, não têm um hábitat concreto, mas quando migram, sobrevoam demoradamente em forma circular (durante duas horas pelo menos), passando de locaclidade a localidade; na tradição umbundu, estas aves são raras e só aparecem para anunciar a proeminência da morte de importantes figuras da comunidade ou do País, ou ainda de uma catástrofe. A sua aparição simboliza a presença de espíritos ancestrais que visitam os seus descendentes, alertando-os para situações catastróficas que se avizinham. As aves como onduva e epumumu são sagradas por simbolizarem as linhagens do poder, e também as espécies vegetais como é o caso da árvore denominada Ulemba ${ }^{11}$ ou Mulemba em vernáculo, também conhecida como Ficus Thonningii ou simplesmente figueira africana por simbolizar a ancestralidade das linhagens do Poder Real, da comunidade e dos habitantes que a domesticam de geração em geração; além de considerá-la como árvore sagrada que providencia sombra em abundância que alberga as sessões de julgamento costumeiro e de outras cerimónias comunitárias, a Ulemba exerce ainda a função de para-raios que repele os relâmpagos durante o periodo das chuvas. Na mesma senda, realizam funerais em espaços florestais com uma densa vegetação, delimitando-os como Cemitérios Santuários $^{12}$, por se considerar a floresta como a fonte primária da vida e espaço adequado para acomodar os espíritos; ainda que as comunidades deixem de realizar funerais nesses espaços as florestassantuários permanecem definitivamente com o mesmo estatuto, sendo por isso proíbida qualquer espécie de ação antrópica sobre elas; todos os membros das

11 Segundo Marques (2012) em Tese de Doutoramento defendida na Universidade Estadual de Campinas SP-Brasil sob o Título: O Carvalho e a Mulemba: Angola na Narrativa Colonial Portuguesa, esta árvore simboliza o espírito em forma concreta, que encarna um tipo de princípio vital do próprio espírito da comunidade - um lugar de contacto com os espíritos ancestrais nela personificados.

${ }^{12}$ Os Cemitérios Santuários são espaços florestais com uma densa vegetação onde é proíbido o derrube de árvores e a realização de qualquer atividade produtiva ou antrópica. 
comunidades ovimbundu partilham do mesmo sentimento de reverência ${ }^{13} \mathrm{a}$ estes santuários.

Os ovimbundu concebem a natureza como obra de Deus (Ente Supremo), uma realidade material e espiritual do universo ou da ordem cósmica, cuja estrutura compreende entes invisíveis ou espirítos intermediários com funções diversas, os ecossistemas e seus componentes, alguns dos quais são sagrados, por neles estarem encarnados os ancestrais ou espíritos protectores das linhagens, dos clãs ou famílias alargadas. No quadro da reverência aos componentes ecossistémicos, os ovimbundu classificam os tipos de vegetação cujas denominações variam entre ussengue (floresta densa), em que a exploração agrícola requer autorização das entidades costumeiras que guardam os segredos sobre a mesma e por ser considerada como reserva comunitária especial, que só pode ser atribuida à familias seculares que respeitam as regras de uma agricultura ecológica e os ciclos de regeneração dos solos; essissi ou estepe onde a exploração agrícola pode ser exercida por todos sem grandes restrições; e enyala ou planície ribeirinha que pelas suas características pode ser explorada no periodo de seca ou cacimbo. Além desta classificação os ovimbundu concebem 0 tempo pelas características sasonais, cuja diferenciação obedece a critérios climáticos que definem a temperatura (calor, humidade, frio) e condicionam as práticas agrícolas tradicionais a serem aplicadas para cada tipo de clima. Assim, ondombo corresponde à estação chuvosa periodo apropriado para a realização de todas as atividades agrícolas; okwenye equivale à estação seca em que as atividades agrícolas só se realizam nas margens dos rios, nas planícies (pradarias ribeirinhas) ou com o concurso de canais artificiais de irrigação; Enyenye expressa alta temperatura; e otchitanya que corresponde a estiagem ou seca temporária.

Os estudos disponíveis, apesar de serem ainda escassos espelham um conjunto de práticas tradicionais de sustentabilidade em quase todas as nações africanas. Maindo, Bambu e Ntahobavuka (2017) referem que as populações Bali de Alibuku, os Mbole de Yaisikia, Yatange e Yalokombe, assim

\footnotetext{
${ }^{13}$ Além das florestas-santuários, os ovimbundu reverenciam também as montanhas, lagos e lagoas, assim como aquelas florestas onde realizam em separado as escolas iniciáticas (feminina e masculina).
} 
como os Kumu de Banango, Kisesa, Biaro, Bayangana e Bakilo que habitam a periferia de Kisangani na República Democrática do Congo, realizavam, até bem pouco tempo, cultos aos ancestrais e cerimónias iniciáticas masculinas de passagem da adolescência para a vida adulta, precedidas de um acto de circuncisão nas denominadas florestas sagradas ${ }^{14}$.

Sanou (2001) ${ }^{15}$ assinala que, entre os Madare de Burkina Faso, o universo é obra de Wuro (Deus); a natureza e o homem emanam deste Ente Supremo, invisível, omnipotente, omnipresente e omniciente que delegou os seus poderes ao Sogo, espírito da floresta responsável pela gestão do meio ambiente na ordem espiritual. Depois de Sogo vem o Do, o espírito fundador da etnia Madare na ordem material de seres viventes, com quem estabeleceu um pacto antes de fundar a comunidade. Segundo este autor, ao fundar a comunidade, Do terá possivelmente recebido orientações sobre os espaços e outros entes considerados como seres sagrados (animais e vegetais) e seres personificados e divinizados (lagos, lagoas, montanhas, etc) que devem merecer a proteção de todos os habitantes. Enquanto espírito da etnia Madare Do aparece materializado em muitos seres da natureza, quer sejam animais, e/ou vegetais como é o caso da palmeira que simboliza o Do propiciador da tranquilidade do lar familiar. Assim, a palmeira, o neré e a karité são espécies vegetais sagradas indispensáveis à vida e ao bem-estar que devem ser protegidas por todos os membros da etnia Madare.

Para o povo Oromo da Etiopia, o valor da natureza está fundamentalmente vinculado à utilidade que o homem faz dela e qualquer tentativa de deteriorá-la acarreta danos irreparáveis a existência da presente e da futura geração. Com esta visão de mundo, os Oromo dedicam especial atenção observando os ciclos da natureza, o início da época chuvosa, o movimento das estrelas, os ciclos solares, a crista das aves, o comportamento dos animais domésticos e selvagens e o estado das árvores, para orientarem os problemas práticos da vida presente e futura. Desta observação cuidadosa elaboram conhecimentos sobre a vida humana, a vida animal, o crescimento dos vegetais, os meses de chuva necessários para o plantio de determinadas

\footnotetext{
${ }^{14}$ Atualmente existe uma tendência de abandono dessas realizações entre aquelas populações da RDC.

${ }^{15}$ Comunicação apresentada no Seminário-Atelier realizado de 18 a 21 de Junho/2001 em Ouagadougou (burkina Faso).
} 
espécies de árvores, o tratamento a dar às culturas, o tempo apropriado para a colheita dos produtos cultivados, etc. Mas, é, sobretudo, a sua concepção moral - a saffuu que serve de fundamento ético para regular o comportamento do homem em condições diversas da vida, principalmente as relações mútuas que se estabelecem na ordem cósmica. Saffuu orienta o homem a abster-se de actos malévolos e da violência, não só na relação com os seus semelhantes, mas também com os animais, os vegetais e outros componentes da natureza; enfim, reger-se pela ética saffuu pressupõe respeitar todos os componentes da natureza incluíndo as divindades Workineh (2004).

Destas concepções de mundo dos autóctones africanos desponta uma moral orientada para a sustentabilidade ambiental que preside a conduta do homem na sua relação com a natureza e com seus semelhantes, e confere legitimidade à proibição de qualquer tentativa de exploração exacerbada de recursos minerais, das espécies animais e vegetais sacralizadas ou não, a destruição de montes e montanhas ou ainda, a obstrução de lagos, lagoas e rios por motivos meramente económicos.

\section{OS FUNDAMENTOS DA SUSTENTABILIDADE NA COSMOVISÃO INDÍGENA LATINOAMERICANA}

Em 2005, a Comissão Económica para América Latina (CEPAL) estimava que a população indígena poderia ser calculada em 50 milhões de habitantes, representando cerca de $12 \%$ do total da população da América Latina cifrada na altura em cerca de 500 milhões. Este universo populacional apresenta uma grande diversidade étnica e cultural no interior de cada estado; apesar dessa diversidade étnica e cultural, os indígenas partilham do mesmo pensamento e do mesmo sentimento de serem um povo originário que tem um vínculo especial com a terra. O sentimento de serem um povo originário está claramente espelhado no guia de aprendizagem das organizações e comunidades indígenas, onde se pode ler:

Somos un conjunto de pueblos hermanos ancestrales, amazónicos, andinos y costeños, profundamente arraigados a nuestros territorios, ubicados ahora dentro de los domínios del Estado peruano, pero que existimos mucho antes del mismo. Nos unen las mismas necessidades, las mismas demandas y las mismas expectativas, por eso nos reconocemos como semejantes. Nosotros somos diversidad de la vida que aprendimos de nuestros ancestros. Nos unen lazos 
culturales muy antíguos, como nuestra lengua, nuestra historia y nuestra propiá concepción del mundo. (Fundo Indigena, 2007, p. 15)

A vida entre os indígenas rege-se por alguns princípios básicos, designadamente, a visão que se tem de homem não como dono do mundo, mas sim, como parte integrante da natureza, a primazia da comunidade sobre o individuo, a reciprocidade, a redistribuição de bens e recursos, o rigor na observância de valores éticos e espirituais, quando se trata da relação com o meio natural e com a comunidade Deruyttere (2001). Esta qualidade se evidencia nos conhecimentos que possuem sobre a ecologia e no modo como estas populações lidam com as questões de equidade e equilíbrio. Os andinos, por exemplo, observam com rigor os quatro princípios que regem a sua cosmovisão: 1) a relacionalidade, ou seja, no universo está tudo relacionado; os seres e as coisas existem não por si mesmo senão pela relação que estabelecem entre si. Esta pode ser de ordem afetiva, ética, estética, ecológica e produtiva. Ninguém, nem mesmo o divino, o sagrado estão fora deste princípio. 2) O princípio da correspondência, que se manifesta em todos os seres do universo; o que ocorre com os planetas e as estrelas afeta aos homens, aos animais, às plantas, aos minerais e à água. 3) O princípio da complementaridade, que esclarece melhor os dois primeiros; os seres e as ações articulam-se e complementam-se mutuamente. 4) O princípio da reciprocidade, que esclarece, praticamente a razão de ser das coisas, dos seres e dos fenómenos do universo; tudo obedece à lógica da retribuição. Devemos retribuir à terra, ao céu, aos nossos irmãos que são os animais, as plantas, as montanhas e os rios; aos nossos irmãos propriamente, aos pais, aos deuses e a nós mesmos Fundo Indígena (2007). A reciprocidade deve ser praticada em todas as esferas da vida, quer seja, afetiva, social, cultural, política, económica, religiosa, etc.

A cosmovisão indígena se fundamenta na relação harmónica e holística entre todos os seres da terra, que é parte da mãe-natureza e do universo; a terra constitui-se então numa base da cosmovisão indígena, pois consideramna como a matriz da identidade cultural, sobre a qual têm uma missão ancestral de defendê-la e conservá-la por serem todos filhos da mãe-natureza. A terra é considerada como a mãe Pachamama e é sagrada. Como mãe, Pachamama encerra vários significados e pode ser objeto de uma série e 
interpretações; ora como expressão espaço-temporal; ora como lugar onde se experimenta a maternidade em kay pacha COMPAS/AGRUCO (2001), e onde tudo nasce e se desvanece: os homens, os animais, as vegetais, os minerais, a água, os rios, os fenómenos naturais, o solo, a chuva, os formigueiros, os poços, os labirintos, etc.

Um outro aspeto de destaque na cosmovisão indígena é a capacidade de predição do clima, considerado como um componente fundamental para a regeneração e conservação da biodiversidade; consiste essencialmente na observação minuciosa e interpretação do comportamento de fenómenos físicos, astronómicos, dos animais e vegetais para predizer o clima que se avizinha. Muitas espécies vivas teriam desaparecido se não tivessem a capacidade de pressentir e adaptar-se as intempéries da mãe-natureza. As populações indígenas reproduzem na atualidade esta capacidade herdada da experiência e da sabedoria milenar construída por ancestrais andinos e que tem uma relevância incomensurável no desenvolvimento das atividades agrícolas e na preservação da biodiversidade no planeta.

O presente estudo abre horizontes para um novo olhar sobre aqueles povos que a mundialização estigmatizou, marginalizou e rotulou como indígenas ou gente sem racionalidade e sem história. As populações autóctones e/ou indígenas de África, Ásia e América Latina desenvolveram, ao longo da história, uma forma própria de agir, ser e estar no mundo; construíram uma concepção de homem totalmente vinculado e comprometido com a mãenatureza da qual emanam e devem obediência, precisamente porque perceberam, desde antanho, que a sua existência no mundo material depende da importância que se dá a todos os seres do universo e da sua sacralização como uma totalidade da qual eles próprios fazem parte. Estas populações não concebem a ideia de um homem desnaturalizado e ingrato, que se rebela contra o berço que the viu nascer. Para estas populações, a sustentabilidade não é um dogma para ser pronunciado de forma repetitiva no discurso ambientalista contemporâneo. É, portanto, uma questão existencial e vital que interpela a consciência humana para uma introspeção e que deve orientar as suas ações quotidianas. Por isso empreenderam uma observação refinada de tudo quanto existe no universo e elaboraram um conjunto de experiências vitais sem as quais a vida estaria mais encurtada; trata-se da convivência com a terra 
e seus elementos bióticos e abióticos, transformação respeitosa do meio ambiente e uso racional dos recursos da natureza, adoção de comportamentos e atitudes não predadoras perante as espécies animais e vegetais, limitação da pegada ecológica, experiência e interação com a natureza em termos de sagrado e cuidados, apego à mãe-natureza e consolidação de uma visão holística do mundo e da vida social, material e sagrada. Estas experiências não seriam realizáveis sem a observância de um conjunto de princípios, nomeadamente, o respeito aos limites da natureza, cuidados com os ciclos da natureza, respeito para com outras formas de vida, não violentar a natureza, produzir o necessário para sustentar a vida, atribuir à natureza uma qualidade sagrada, considerar a terra como um bem inalienável não comercializável e tomar as decisões em comunidade.

Entretanto, a mundialização, o modelo neoliberal de desenvolvimento e a globalização ignoraram e perverteram estes valores, impondo padrões de uma cultura hegemónica, fundada na violência e busca incessante do lucro. Esta estratégia de grupos hegemónicos que auspicia a emergência de novas formas de neocolonização em todo o mundo, impõe aos africanos, asiáticos e latino-americanos uma situação de contingência, obrigando-os a adotar atitudes depredadoras e de violência contra o meio ambiente, a natureza, na busca de alternativas para mitigar a pobreza. Para inverter esta tendência, os governos, as organizações da sociedade civil e as igrejas devem realizar um conjunto de tarefas pendentes, que consistiriam em visibilizar e valorizar os conhecimentos autóctones e indígenas, promover um diálogo intercultural, abandonar a leitura bucólica desses povos e integrar os aportes da visão e do conhecimento autóctone ou indígena na construção de uma cultural sustentável global.

\section{CONCLUSÕES}

Desde tempos imemoráveis que a África vem elaborando conhecimentos experimentados pela prática quotidiana, cuja essência e valor permeiam a mentalidade dos seus povos. A África não é um continente alheio aos conhecimentos sobre a sustentabilidade ambiental, dos ecossistemas e da biodiversidade tal como se apregoa em alguns círculos acadêmicos e políticos; 
o que falta em África é a sensibilidade e a determinação das elites que controlam o poder político em transformar e traduzir os conceitos e os conhecimentos acumulados, para o discurso político e para a linguagem de senso comum, a fim de que sejam conhecidos e reconhecidos por todos aqueles que se interessam pela construção de uma cultura de sustentabilidade do nosso planeta.

A cultura tradicional dos indígenas da África e da América Latina constitui um rico património imaterial respaldado por conhecimentos e experiencias vitais que podem subsidiar a resolução da crise ambiental e global que assola o mundo atual. Este rico património imaterial não surge do acaso, pois é produto de uma racionalidade construída através de um intenso relacionamento com realidades que estruturam o universo - a principal fonte da sabedoria universal. Ao relacionarem-se com uma diversidade de entes materiais e espirituais, os autóctones africanos e os indígenas da América Latina formularam princípios, códigos éticos e elaboraram experiências práticas que lhes permitem estar neste mundo em harmonia com a natureza, isto é, viver sem causar danos irreparáveis aos ecossistemas ou provocar desequilíbrios na biosfera. Este rico património auspiciado por uma ética de amor reciproco e não-violência entre todos os seres do universo pode subsidiar a construção de uma cultura de sustentabilidade, se for reconhecido, valorizado e adotado por todos os habitantes do nosso planeta. Pensamos, que, esta é a utopia que deve nortear a renovação dos sistemas educativos e a formulação de políticas em todos os domínios da vida.

\section{REFERÊNCIA}

BATANOLLI, J.A.R.; MILIOLI, G. (2016): Crise planetária: As abordagens para seu entendimento e superação considerando novas concepções científicas e culturais. Disponível:RevistaRBCIAMBabesdn.org.br/publicações/rbciamb/ed42/RBCIAMB_n42_37-55.pdf

BELCHIOR, G.P.N.; VIANA, I.C. (2016): Sustentabilidade e Meio Ambiente: Reflexões sob o olhar da complexidade. Revista AREL FAAR, Arquimenes, RO, v4.№ 1, pp. 72-90. Recuperado de: 183-texto do artigo-400-1-1020170225.pdf

BUTARÉ, Innocent (2003) Pratiques culturelles, la sauvegarde et la conservation de la biodiversité en Afrique de l'Ouest et du Centre: Actes 
du Séminaire-Atelier de Ouagadougou (Burkina Faso) du 18 au 21 Juin 2001. Edition du Centre de Recherches pour le Developpement International

CANOTILHO, J.J.G. (2010): O princípio da sustentabilidade como princípio estruturante do Direito Constitucional. Recuperado de:

www.scielo.mec.pt/pdf/tek/n-13a 02.pdf

CAVALCANTI, Clóvis (1994) Desenvolvimento e Natureza: Estudos para uma sociedade sustentável. INPSO/FUNDAJ, Instituto de Pesquisas Sociais, Fundação Joaquim Nabyco, Minsitério de Educação, Brasil. Recuperado de: http://168.96.200.17/ar/libros/brasil/pesqui/cavalcanti.rtf

COMPAS/AGRUCO (2001): Cosmovisión Indígena y biodiversidade en América Latina. Recuperado de:

https://wwwacademia.edu/33229444/cosmovisión indigena y biodiversidad e n américa latina.pdf

DERUYTTERE, A. (2001) Pueblos indígenas, globalización y desarrollo con identidade: algunas reflexiones de estrategia. Recuperado de: red.pucp.edu.pe/ridei/wp-content/uploads/biblioteca/081233.pdf

FERRER, G.R. (2012): Calidad de vida, medio ambiente, sostenibilidad, y ciudadania . Construímos juntos el futuro? Revista NEJ electronica, v. 17, n. 3, pp. 305-326

FONDO INDÍGENA (2007): Módulo de História y Cosmovisión Indígena. Guia de aprendizaje colectivo para organizaciones y comunidades.

Recuperado de: www.fondoindígena.org/wp-content/uploads/2011/08/MóduloHistória.pdf

FREITAS, J. (2012): Sustentabilidade. Direito ao futuro.Recuperado de: https://www.travessa.com.br/sustentabilidade-direito-ao-futuro-2-ed2012/artigo/1e5a5df2-2864-42e8-9942-ce74a1ec69fe

GADOU, D. (2001): La preservation de la biodiversité. Les reponses de la tradition africaine - Journal of the Pan african Anthropological Association Number 2 volume VIII October, 2001, pp. 178-199.Recuperado de: DOI: http://dx.doi.org/10.4314/aa.v8i2.23109

HERRERO, L.M.J. (2000): Desarrollo sostenible: Transición hacia la coevolución global. Madrid. Ediciiones Piramide

LEFF, E. (2001): Saber Ambiental. Sustentabilidade, racionalidade, complexidade, poder. Recuperado de:

https://edisciplinas.usp.br/pluginfiles.php/4245135/mod.resource/content/3/sabe r\%20-Ambiental.pdf

(2004): Racionalidad Ambiental. La reapropriacion social de la naturaleza. México. Siglo Ventiuno editores.

LOUREIRO, C.F.(2012): Sustentabilidade e educação um olhar da ecologia política. Brasil. São Paulo. Cotez 
MAINDO Alphonse, BAMBU Papy e NTAHOBAVUKA Adeline (2017) Concilier les savoirs endogènes et les moyens d'existence en Republique Democratique du Congo. Une stratégie de gestion durable de la biodiversité biologique autour de Kisangani. Tropenbos RD Congo.

MEMEL FOTÊ, H. (1998): Trois essais philosophiques sur l'environnement et societé en Afrique. in: Bulletin du GIDLI-CI, № 17 Centre I.R.D, Abidjan, pp. $37-45$

MORENO, O.B.A. (2011): La crisis ambiental como processo. Un análisis reflexivo sobre su emergência desarrollo y profundización desde la perspectiva de la teoria crítica (Tesis Doctoral), Universitat de Girona, España).

Recuperado/https://www.tdx.cat/bitstream/handle10803/7671/tobam.pdf?seque nce $=5$ \&isAllowed $=\mathrm{y}$

MORIN, E.; KERN, A.B. (2003): Terra-Patria Recuperado/https://edisciplinasusp-br/pluginfile.php/307749/mod_resource/content/1/livro\%20-

\%20Terra\%20Pátria\%20-\%20EDGAR\%20Morin.pdf

MORIN, E. (2011): La via para el futuro de la

humanidade.Recuperado/https://www.uv.mx/Veracruz/cosustentaver/files/2015 /09/20.la_via_Para_el_futuro_de_la_Humanidad.pdf

OST, François (1995) A natureza à nargem da lei: a ecologia à prova do direito. Editions La Decouverte. Portugal. Instituto Jean Piaget

SANOU, Bruno Doti (2001) Gestion des espèces végétales sacrées dans le milieu Madare au BurkinaFaso: cas du rônier, du karté et du neré. In: BUTARÉ Innocent (DIR) (2003)

Pratiques culturelles, la sauvegarde et la conservation de la biodiversité en Afrique de l'Ouest et du Centre: Actes du Séminaire-Atelier de Ouagadougou (Burkina Faso) du 18 au 21 Juin 2001. Edition du Centre de Recherches pour le Developpement International

WORKINEH, Kelbessa (2004) La Réhabilitation de l'Etique Environnementale Traditionnelle en Afrique. Presses Universittaires de France. Diogene Vol. 3, № 297 pp. 20-42. Recuperado de: https://www.cairn.info/revue-diogène-2004-3page-20.htm 